\title{
ОПЫТ ПРОДУКТИВНОГО РЕАГИРОВАНИЯ: К ВОПРОСУ О ПЕДАГОГИЧЕСКИХ СМЫСЛАХ ПОНЯТИЯ
}

\section{EXPERIENCE OF PRODUCTIVE RESPONSE: ON THE QUESTION OF PEDAGOGICAL MEANINGS OF THE CONCEPT}

\author{
M. Yurova \\ Yu. Kudinova \\ V. Zozulya
}

Summary: The purpose of the article: to consider the personal and professional experience of a future teacher in terms of productive response to dynamically changing manifestations of educational practice, to substantiate the content of the concept of "experience of productive response". The methodology is based on personal-activity, subject-based and event-based approaches. The content of the concepts "experience", "personal and professional experience", "productive experience", "response experience" is analyzed. The idea of detailing the broad concept of "personal and professional experience" on the grounds of productivity and response as an element of behavior and activity is substantiated. The formation of the experience of productive response is based on intellectual, need-motivational and self-correcting mechanisms.

Keywords: experience, personal and professional experience, productivity, response as an element of behavior and activity of the teacher, experience of productive response.

\author{
Юрова Мария Сергеевна \\ Аспирант, Воронежский государственный \\ педагогический университет \\ yurova_maria_s@mail.ru \\ Кудинова Юлия Валерьевна \\ К.и.н., доцент, Воронежский государственный \\ педагогический университет \\ kudjulia@mail.ru \\ Зозуля Вероника Викторовна \\ Аспирант, Воронежский государственный \\ педагогический университет \\ pp.rosnou14@yandex.ru
}

Аннотация: Цель статьи - рассмотреть личностно-профессиональный опыт будущего учителя в части продуктивного реагирования на динамично изменяющиеся проявления образовательной практики, обоснование содержания понятия «опыт продуктивного реагирования». Основу методологии составили личностно-деятельностный, субъектный и событийный подходы. Проанализировано содержание понятий «опыт», «личностно-профессиональный опыт», «продуктивный опыт», «опыт реагирования». Обосновывается идея 0 возможности детализации широкого понятия «личностно-профессиональный опыт», для детализации использованы два основания: продуктивность и реагирование как элемент поведения и деятельности. В основе формирования опыта продуктивного реагирования лежат интеллектуальный, потребностно-мотивационный и самокоррекционный механизмы.

Ключевые слова: опыт, личностно-профессиональный опыт, продуктивность, реагирование как элемент поведения и деятельности педагога, опыт продуктивного реагирования.

целостности, но и отдельных составляющих.

В данной статье мы рассмотрим личностно-профессиональный опыт будущего учителя в части продуктивного реагирования на динамично изменяющиеся проявления образовательной практики, предложим обоснование содержания понятия «опыт продуктивного реагирования». Основу методологии при этом составят личностно-деятельностный, субъектный и событийный подходы.

Категория «опыт» используется широким кругом отраслей научного знания, что в итоге позволяет выделить ее инвариантные характеристики, фиксируемые, в том числе, в словарных определениях:

- сущностная характеристика: результат активного взаимодействия с объективным миром, осознание «законов этого мира и общественной практики» [13];

- структурная характеристика: определенная совокупность знаний, умений и навыков, освоенных и усвоенных в практике. 
Философские представления об опыте, сформированные в исследованиях сенсуалистов, материалистов, рационалистов, субъективистов и др., несмотря на различие подходов, закрепили факт универсальности и целостности человеческой деятельности как основы опыта; его зависимость от чувств, воли, ценностного отношения; генезис опыта от врожденного к социальному, определяющему развитие «специфически человеческой психики» [6]; интегрирующую роль сознания.

Психология сформировала традицию изучения рассматриваемого явления, базирующуюся на определении места опыта в структуре личности, его влиянии на личностное и профессиональное развитие. Опыт определяется как «динамическая информационная система, включающая сведения о внешнем и внутреннем мире, получаемая непосредственно- чувственным и опосредованным путем, наполненная личностным смыслом и определяющая стратегию, успешность деятельности $<\ldots$..>. В структуре опыта четко выделяют денотативное содержание, операциональное содержание и аффективно-мотивационное содержание. Во всех этих компонентах отражены когнитивные, оперативные и интимно-личностные элементы деятельности» [11, с. 92]. Значительное внимание уделяется как субъектному опыту, так и роли субъекта и полисубъекта в становлении и развитии различных видов опыта. Л.П. Буева, А.А. Сидорова и др. рассматривают опыт как философскую категорию, раскрывая понятие через форму духовнопрактического освоения действительности, которая служит фундаментом для духовного постижения предметов, а также оказывается непосредственно связанной с преобразованием окружающей действительности в соответствии с ключевыми социальными потребностями субъекта. Самостоятельным направлением изучения опыта стала его деятельностная интерпретация (А.Н. Леонтьев и др.).

С точки зрения педагогической культурологии (Н.Б. Крылова, Л.П. Разбегаева и др.) сущностной характеристикой опыта выступает его событийность (что позволяет выделять механизмы формирования опыта в повседневной реальности, а также трактовать опыт как совокупность присвоенных событий), предметность, практическая направленность и незавершенность. Опыт обновляется, осмысливается и присваивается, прежде всего, в результате возможной творческой активности самого человека, отрицающей прежний опыт и выстраивающей новый. Обращается внимание на опыт ценностного самоопределения личности, в рамках изучения которого подчеркивается значение метаоценивания, самооценки, ценностных отношений.

В педагогике использование категории «опыт» также имеет сложившуюся традицию. Интерпретация философского, психологического, социологического, культурологического научного знания о сущности, видах, ме- ханизмах формирования можно отнести к особенностям осмысления опыта в педагогике. Как следствие, у педагогов можно найти отражение всех описанных выше позиций, осмысленных и развитых в контексте специфического педагогического предмета изучения реальности. При этом подчеркивается формируемость опыта как в результате социализирующих воздействий среды и собственной активности личности, так и под влиянием целенаправленных воздействий представителей образовательных систем. Обращается внимание на роль как собственного опыта личности, так и чужого опыта как примера, образца, эталона.

Для педагогического осмысления сущности опыта и механизмов его формирования важное значение имеет вид опыта.

Диалектика предъявления опыта, вхождения в него человека как в данность, последующее освоение и присвоение, преобразование и «возврат» в надиндивидуальное состояние позволило выделить отчужденный и присвоенный опыт (В.В. Кешелава, Ф.И. Минюшев, А.П. Огурцов и др.). Отчужденный опыт одновременно может быть и способом человеческого бытия, источником и средством прогресса, и рефлексивной данностью сознания, способом познания, инструментом и ресурсом образования и развития.

По источнику возникновения И.И. Неясова и А.В. Чегрина выделяют социальный опыт, то есть присвоенный извне, и личностный опыт как продукт саморазвития личности; по виду деятельности: познавательный, трудовой, нравственный, эстетический, коммуникативный и др.; по характеру деятельности: репродуктивный и продуктивный [9]. Под историческим опытом понимают накапливающийся в общественном сознании комплекс представлений о закономерностях социального бытия и общественного развития. Под культурным опытом понимается самостоятельная практика осмысления собственного действия и поведения, понимания и реализации своих личностных возможностей участия в культурных процессах на основе культурных норм деятельности. Основой данного опыта в такой логике становится не знание, а рефлексия практической деятельности, ее анализ, формирование этого новообразования в дальнейшей деятельности. Опыт, прежде всего, имеет накопительно-конструктивный, реконструктивный и субъективный характер.

Подчеркнем, что образовательные практики обращены ко всем видам опыта, большая часть из которых формируется, в том числе, в образовательном процессе. По сути, образовательный процесс сопровождает становление опыта человека как основного процесса.

Педагог не только должен быть носителем и/или интерпретатором, транслятором опыта, но ему необ- 
ходимо понимать механизмы его формирования, в том числе, с учетом возрастных и возможных индивидуальных особенностей, а также владеть методиками формирования опыта. Опыт как критерий определения содержания образования использован в концепции Н.M. Скаткина и И.Я. Лернера, согласно которой содержание образование необходимо представить в виде совокупности таких составляющих, как когнитивный, опыт осуществления способов деятельности, опыт творческой деятельности, опыт отношений личности к миру, к деятельности, к людям. В этой же логике, но применительно к личному опыту выделяет его составляющие С.В. Христофоров: когнитивный, где результатом выступает знание о сущности объекта или явления, стремление к объективному знанию; технологический, включающий в себя непосредственный уровень, контактный уровень, опосредованный визуальный уровень, виртуальный и другие; ориентационный, включает в себя позитивные или негативные эмоции, ценностные ориентиры, оценку, отношения и многое другое [14].

Формирующийся в процессе жизнедеятельности в педагогическом вузе личностно-профессиональный опыт студента исследователи рассматривают как «совокупность практически усвоенных профессиональных знаний, имеющихся навыков и умений, апробированных лично в результате активного взаимодействия с объективным миром социальной практики и отраженных в его сознании способов, норм и правил профессиональной деятельности, социокультурных смыслов и жизненных ценностей, способствующих личностному и профессиональному росту обучающегося» [3]. Структуру этого вида опыта также описывают как единство когнитивных, отношенческих и деятельностных составляющих.

Данный вид опыта можно детализировать, получая в итоге более конкретные описания, позволяющие точнее проектировать педагогическое сопровождение.

Для детализации личностно-профессионального опыта используем два основания: продуктивность и реагирование как элемент поведения и деятельности.

Продуктивность - одна из сущностных характеристик опыта, которая может рассматриваться как внутренняя (изменения в личностном опыте, внутреннем мире, рисунке поведения и деятельности, субъектность; фиксируется актами рефлексии) и/или внешняя (объективация результата, имеющего характер реального продукта; фиксируется актами наблюдения и оценки).

В научных текстах, посвященных опыту, встречаем два варианта использования данной характеристики: продуктивный опыт и опыт продуктивной деятельности.

Продуктивный опыт выражается в активности личности, способной к преобразованиям, отличительной особенностью такой личности становится субъектность, творчество и рефлексия. Противоположностью продуктивного выступает репродуктивный опыт, основанный на воспроизведении и механическом выполнении действий и не связанный с развитием творческого мышления и воображения личности (О.Ю. Елькина [4], Н.М. Игонина [5]).

И.И. Неясова и А.В. Чегрина выделяют следующие признаки продуктивного опыта: является индивидуальным, не передается индивиду биологическим механизмом наследования, а требует активной личностной позиции и творческого освоения; осваивается в результате целенаправленных воздействий и может являться прямым или побочным продуктом определенных видов деятельности; основными способами освоения продуктивного опыта являются продуктивная деятельность, самосознание, рефлексия [9].

Структура продуктивного опыта включает когнитивный («Я знаю»), мотивационно-потребностный («Я хочу»), целеполагающий («Я планирую»), операционный («Я умею»), креативный («Я созидаю»), эмоциональный («Я переживаю»), рефлексивно-оценочный («Я оцениваю») составляющие [4, с. 42].

Опыт продуктивной деятельности рассматривается, прежде всего, в контексте концепций продуктивного образования, теорий копинг-поведения и продуктивной самореализации личности профессионала.

«Продуктивное образование направлено на развитие познавательных и созидательных способностей личности, что позволяет учащемуся овладевать образовательными стратегиями, конструировать личностные знания и опыт познавательной деятельности одновременно с включением его в научные и культурно-исторические процессы в качестве их полноправного участника, взаимодействовать с другими субъектами образовательного процесса и с окружающим миром как активной, самостоятельной, творческой личности (В. С. Леднев, Ю.С. Дик и др.)» [10, с. 223]. Продуктивность фиксируется в:

- измененном характере деятельности (конструктивность, рефлексивность);

- ориентации на результат (социально и личностно значимый, культурно полноценный продукт);

- увеличении доли самостоятельности;

- повышении ответственности личности как субъекта деятельности;

- согласованности с социокультурным фоном реализации деятельности;

- актуализации творческого потенциала субъекта деятельности.

Теоретические основы копинг-поведения начинали формироваться зарубежными исследователями (S. Folkman, R.C. Kessler, R.H. Moss, M.F. Scheier и др.) и нашли 
свое развитие в работах отечественных ученых, занимающихся проблемами стрессовладающего поведения (Л.И. Анцыферова, В.А. Бодров, Л. Г. Дикая, А.Р. Лурия, А.В. Махнач, И.М. Никольская и др.). Именно стрессогенные жизненные события заставляют человека вырабатывать стратегии поведения, разделяемые исследователями на продуктивные (активные, функциональные) и непродуктивные (пассивные, дисфункциональные, подчинение личности интересам и требованиям среды). Ситуации и события, порождающие тревогу и стресс, вызывают не только определенные психозащитные реакции, но и запускают механизмы адаптации, социальное поведение, помогающее справиться с «жизненными трудностями, внутренним напряжением и дискомфортом» [7, с. 211].

В тех случаях, когда речь идет о сфере профессиональной деятельности, имеет значение анализ активной (продуктивной) и пассивной (непродуктивной) стратегий профессионального развития. «Активная стратегия профессионального развития - способность субъекта к активному самостоятельному планированию и построению своей профессиональной карьеры, к принципиальному, осмысленному и ответственному ее регулированию в соответствии с поставленной целью достижения профессионального успеха с учетом существующей социально-экономической ситуации на рынке труда. Пассивная стратегия профессионального развития - безынициативная позиция субъекта в планировании и построении своей профессиональной карьеры, отсутствие принципиального, осмысленного и ответственного стремления к достижению профессионального успеха в условиях конкретной социально-экономической ситуации на рынке труда» [8, с. 83].

Продуктивную самореализацию связывают с жизнетворчеством (Л.А. Коростылева), определенными особенностями мировоззрения, мотивации и самооценки (оптимизм, устойчивые положительные отношения, ориентация на успех в сочетании с реалистичным отношением к действительности). Особенность жизнетворчества - восприятие субъектом своей жизни как объекта творческой активности, преобразование не только окружающей действительности, но и самого себя. По мнению И.В. Бойковой, А.А. Ильина, Е.Ю. Шварцкопф, продуктивная самореализация есть «процесс качественно организованной системы целеполагания и решения задач внутриличностного и поликультурного генеза, позволяющих повышать качество жизнедеятельности и облегчать, модифицировать и обновлять традиционные способы решения задач» [2].

Таким образом, по основанию продуктивности личностно-профессиональный опыт отличается переносом сущностных черт продуктивности на принятие, понимание, мотивированность, применение, преобразование стратегий личностно-профессионального развития, саморазвития, поведения и деятельности, их закрепление, осмысление и апробацию в профессиональных и личностных практиках.

В числе элементов поведения выделим реагирование как сложный комплекс реакций на явления окружающей действительности. Оно предполагает осмысление ситуаций и событий, аффективное отражение, поведенческое и деятельностное выражение. Реагирование возможно на различных уровнях, начиная с физиологического и заканчивая сложными комплексными образованиями (например, сочетание физиологического, импрессивного и экспрессивного при эмоционально-чувственном реагировании).

Рассматривая сущность адекватного и неадекватного реагирования, О.С. Анисимов подчеркивает связь адекватного реагирования с опытом жизнедеятельности и изменениями внутреннего мира личности: «Если переход от реагирования на внешние социокультурные воздействия в рамках приоритета внутренней субъективной динамики и случайности этой динамики с точки зрения внешних требований и ведет к адекватному реагированию, то сам переход возникает лишь через вовлечение внутреннего потенциала адаптивности и через преодоление сопротивления к вынуждающим влияниям. <...> во всех случаях реагирующий на внешние социокультурные воздействия сначала отдает приоритет внутренней динамике и самопроявлениям и лишь затем переходит к установке на требуемую при ориентации на сохранение личностных смысловых установок адаптацию. Требуемое извне выступает как нечто чуждое, и лишь в ходе внутренних трансформаций воспринимаемое внешнее в процессе освоения смысла осваиваемого становится внутренне значимым» [1, с. 41-42]. Автор делает вывод о том, что любой переход к адекватному реагированию на изменяющиеся условия внешней среды, ситуации и события с качественно иными характеристиками предполагают внутренние изменения в интеллектуальном, потребностно-мотивационном и самокоррекционном механизмах.

Обращаясь к фиксируемым в наблюдении элементам поведения и деятельности педагога, обратим внимание на факт реагирования на различные ситуации и события в образовательной среде. С точки зрения эмоционально-чувственного восприятия различаются позитивно и негативно окрашенные профессиональные ситуации и события. Последние требуют:

- полноценного восприятия и многостороннего видения ситуации или события;

- рационального объяснения, исходя из полученных профессиональных знаний, понимания природы и сущности произошедшего;

- принятия случившегося факта как входящего в сферу профессиональной деятельности;

- подбора адекватных стратегий реагирования не только исходя из личностного отношения к про- 
исходящему, но и с точки зрения педагогической целесообразности;

- оценки собственной операциональной подготовленности (могу сделать);

- саморегуляции и контроля общего эмоционального фона;

- собственного поведения и организаторских действий, сообразных ситуации или событию;

- профессиональной рефлексии, направленной на оценку собственной готовности реагировать на ситуации или события подобного типа.

Данная совокупность действий может составить основу опыта продуктивного реагирования.

Таким образом, по основанию реагирования как элемента поведения и деятельности личностно-профессиональный опыт отличает сложный комплекс реакций, адекватный как требованиям ситуации, так и изменени- ям в смысловой сфере личности. В основе формирования опыта реагирования лежат интеллектуальный, потребностно-мотивационный и самокоррекционный механизмы.

Подводя итог, отметим необходимость дальнейшего анализа сущности понятия «опыт продуктивного реагирования» как составляющей личностно-профессионального опыта будущих педагогов. Все усложняющаяся социокультурная среда образовательных систем, трансформации педагогических взаимодействий и отношений превращают педагогическую повседневность в калейдоскоп зачастую негативных и неоднозначных ситуаций и событий. Опыт продуктивного реагирования, формируемый, в том числе, и в процессе обучения в вузе, может стать основой для принятия адекватных решений, обеспечивающих как сбережение здоровья обучающихся и педагогов, так и их личностное развитие.

\section{ЛИТЕРАТУРА}

1. Анисимов О.С. Смысловое реагирование в острых жизненных сюжетах / О.С. Анисимов // Мир психологии. 2017. № 3. С. 41-49.

2. Бойкова И.В. Продуктивное самовыражение и самореализация личности в модели формирования культуры самостоятельной работы / И.В. Бойкова, А.А. Ильин, Е.Ю. Шварцкопф // Гуманитарные научные исследования. 2015. № 11. URL: http://human.snauka.ru/2015/11/13171 (дата обращения: 02.03.2021).

3. Валеева М.А. Личностно-профессиональный опыт студента как объект научно-педагогического исследования / М.А. Валеева // Современные проблемы науки и образования. 2015. № 4. URL : https://science-education.ru/ru/article/view?id=20963 (дата обращения: 01.03.2021).

4. Елькина 0.Ю. Продуктивный опыт младших школьников: состояние и перспективы развития: монография / 0.Ю. Елькина. М.: Флинта, 2012. 146 с.

5. Игонина Н.М. Генезис взглядов на проблему формирования продуктивного опыта личности / Н.М. Игонина // Категория «социального» В современной педагогике и психологии: сборник материалов конференции. Тольятти: Зебра, 2016. С. 35-39.

6. Касаткина С.С. Философская категория «опыт» как элемент педагогического сознания / С.С. Касаткина // Опыт как важнейшая составляющая социализации субъектов образовательного процесса : Материалы международной научно-практической конференции, $28-29$ апреля 2010 г., Саратов. В 2-х частях. Саратов: 000 «Издательский Центр «Наука», 2010. Ч. 1. С. 32-33

7. Крюкова Т.Л. Основные подходы к изучению совладающего поведения в зарубежной и отечественной психологии / Т.Л. Крюкова // Вестник КГУ им. Н.А. Некрасова. 2004. № 4. С. 209-216.

8. Малова 0.В. Особенности самореализации людей с продуктивной и непродуктивной стратегиями профессионального развития / 0.В. Малова // Вестник Ленинградского государственного университета им. А.С. Пушкина. 2012. Том 5. Вып. 3. С. 81-92.

9. Неясова И.А. Формирование продуктивного опыта как психолого-педагогическая проблема / И.А. Неясова, А.В. Чегрина // Осовские педагогические чтения «0бразование в современном мире: новое время - новые решения»: сб. науч. ст. по материалам междунар. науч.-практ. конф. Саранск: Мордов. гос. пед. ин-т., 2018. С. 168-172.

10. Пластинина Ю.Л. Роль учителя в формировании опыта продуктивной учебной деятельности у школьников / Ю.Л. Пластинина // Вектор науки ТГУ. 2011. № 4. C. 223-225.

11. Семенцова К.С. Теоретический обзор исследований опыта личности как психологического феномена / К.С. Семенцова // Вестник Псковского государственного университета. Серия: Социально-гуманитарные науки. 2012. № 1. С. 91-97.

12. Скуратовская Н.А. Продуктивный опыт школьников как современная педагогическая проблема / Н.А. Скуратовская // Наука и социум: материалы всероссийской научно-практической конференции с международным участием. Новосибирск: Сибирский институт практической психологии, педагогики и социальной работы, 2018. С. 100-107.

13. Толковый словарь русского языка: 72500 слов и 7500 фразеологических выражений / С.И. Ожегов, Н.Ю. Шведова; Российская АН, Ин-т рус. яз., Российский фонд культуры. М.: Азъ, 1994. - 907 с.

14. Христофоров С.В. Опыт как педагогическая категория / С.В. Христофоров // Вестник Оренбургского государственного университета. 2005. № 7. С. 180-184.

( Юрова Мария Сергеевна (yurova_maria_s@mail.ru), Кудинова Юлия Валерьевна (kudjulia@mail.ru), Зозуля Вероника Викторовна (pp.rosnou14@уandex.ru).

Журнал «Современная наука: актуальные проблемы теории и практики» 